\title{
Urinary CXCL10: a marker of nephritis in lupus patients
}

\author{
M.A. Marie', R.E. Abu Khalil' ${ }^{2}$ H.M. Habib ${ }^{3}$ \\ 'Department of Internal Medicine, Cairo University; \\ ${ }^{2}$ Department of Clinical and Chemical Pathology, Cairo University; \\ ${ }^{3}$ Department of Rheumatology and Rehabilitation, Mansoura University, Egypt
}

\begin{abstract}
SUMMARY
Systemic lupus erythematosus (SLE) is a connective tissue disease characterized by the formation of autoantibodies and immune complexes. Lupus nephritis is one of the hallmark features of SLE. CXCL10 is a chemokine secreted by IFNg- stimulated endothelial cells and has been shown to be involved in the pathological processes of autoimmune diseases. The objective was to measure urinary CXCL10 in SLE patients, to compare levels between nephritis and non-nephritis groups and to study its correlation with other variables.

Sixty lupus patients were enrolled in our trial. Thirty patients had lupus nephritis and the other 30 were without evidence of lupus nephritis. Thirty healthy subjects were willing to participate as a healthy control group. Renal biopsy was performed for lupus nephritis group. Urinary CXCL10 was measured using the ELISA technique. Serum creatinine, C3, C4 and $24 \mathrm{~h}$ urinary proteins were measured. Lupus activity was assessed using systemic lupus erythematosus disease activity index (SLEDAI) scoring system. Renal activity was measured using renal activity scoring system. CXCL10 was significantly higher in lupus nephritis patients than in lupus patients without nephritis. CXCL10 was significantly correlated with renal activity score, 24 hours urinary proteins and the SLEDAI score. It is highly valid predictor of SLE nephritis with high sensitivity and specificity.

CXCL 10 a highly sensitive and specific non-invasive diagnostic tool for lupus nephritis patients.
\end{abstract}

Key words: CXCL10; lupus nephritis.

Reumatismo, 2013; 65 (6): 292-297

\section{INTRODUCTION}

ystemic lupus erythematosus (SLE) is $\checkmark$ a connective tissue disease characterized by the formation of autoantibodies and immune complexes (1). Lupus nephritis (LN) is one of the hallmark features of SLE, seen in 40-60\% of patients (2). It is an important cause of morbidity and mortality. One approach to improve outcome is to diagnose patients early. Late diagnosis of LN correlates with a higher frequency of renal insufficiency and end stage renal disease, underlining the importance of early diagnosis. While kidney biopsy is a valuable tool, it is an invasive procedure that is not always feasible and cannot be performed repeatedly. Moreover, it may not be representative, as only a limited number of glomeruli are sampled (3).

Corresponding author: Hisham M. Habib Department of Rheumatology and Rehabilitation, Mansoura University, Egypt. E-mail: hesham_habib@yahoo.com
CXCL10ia a chemokine also known as INFg-inducible protein 10 (IP-10); it is secreted by IFN- $\gamma$ stimulated endothelial cells, fibro- blasts and monocytes. CXCL10 promotes migration of $\mathrm{T}$ cells to sites of inflammation and is also known to play a role in the down-regulation of angiogenesis, together with its receptor, CXC receptor 3 (CXCR3) (4). CXCL10 is highly expressed in a wide range of human diseases. It has been shown to be involved in the pathological processes of three main human disorders namely infectious, inflammatory and autoimmune diseases (5). In SLE patients, CXCL10 levels in serum are highly elevated and correlate with levels of disease activity (6). Interestingly, urinary expression of messenger RNA (mRNA) for both CXCR3 and CXCL10 has been shown to correlate with nephritis activity, being up-regulated in patients with active lupus nephritis and not detectable in healthy control subjects (7).

\section{Objectives}

The aim of the current study was to measure urinary CXCL10 in a cohort of SLE 
patients, to compare its level between nephritis and non-nephritis groups and to study its correlation with other variables including $24 \mathrm{~h}$ urinary proteins, SLEDAI score, C3, C4, serum creatinine, renal activity score and renal biopsy grading.

\section{MATERIALS AND METHODS}

In our case control study, we recruited 60 patients diagnosed as having systemic lupus erythematosus who fulfilled the American College of Rheumatology (ACR) classification criteria for SLE (8). Patients were divided into two groups. Group one: involved 30 patients with evidence of lupus nephritis as having $24 \mathrm{~h}$ urinary protein $>0.5 \mathrm{gm}$ or active urinary sediment in the form of either microscopic or macroscopic hematuria or white cell cast with or without elevated serum creatinine. Group two: involved 30 SLE patients without any evidence of lupus nephritis.

These two groups were compared with 30 healthy age- and sex-matched control subjects. All patients were subjected to careful history taking, full clinical examination and routine laboratory investigations. SLE disease activity was assessed by the systemic lupus erythematosus disease activity index (SLEDAI) (9). A complete hemogram, chemistry, urinalysis, $24 \mathrm{~h}$ urinary proteins and serological tests (C3 and $\mathrm{C} 4)$ were performed all patients. Anti-dsDNA and anti C1q was measured for all patients. Renal biopsy was performed only for SLE patients with clinical evidence of nephritis. Histological grading was done according to ISN-RPS criteria by 2003 (10).

The study was approved from hospital ethical committee and a written informed consent was taken from all individuals who agreed to contribute in the study after full information about the study and the related procedures.

\section{Urinary CXCL10 determination}

CXCL10 levels in urine were determined by sandwich enzyme-linked immunosorbent assay (ELISA) (Opt EIA Systems, BD Biosciences, San Diego, CA, USA) ac- cording to the manufacturer's instructions. Levels were measured within 5 days of performing kidney biopsy.

\section{Renal activity score}

Renal activity score was measured using the following criteria: proteinuria $0.5-1$ $\mathrm{gm} /$ day $=3$ points, proteinuria $>1-3 \mathrm{gm} /$ day $=5$ points, proteinuria $>3 \mathrm{gm} /$ day $=11$ points, urine red blood cell count $>/=5 /$ hpf $=3$ points, urine white blood cell count $>/=5 / \mathrm{hpf}=1$ point $(11)$.

\section{Statistical analysis}

For statistical analysis, statistical software SPSS 10.0 (SPSS, Chicago, IL, USA) was employed. Quantitative data were expressed as mean $\pm \mathrm{SD}$. For comparison between patients and controls, and comparison of clinical features and pathological data of patients, the one way ANOVA analysis of variance and Chi-square test were used. For correlation between CXCL10 versus other variables, correlation coefficient test was used. Statistical significance was considered as $\mathrm{p}<0.05$.

\section{RESULTS}

\section{Study population}

Demographic, clinical, and some relevant laboratory characteristics of the patients are summarized in Table I. In general, the study group comprised 60 SLE patients (55 females, 5 males) with a mean age of $23 \pm 5.5$ years. There was no statistically significant difference in age, gender and disease duration between groups. SLEDAI score was calculated including the renal activity score in both SLE groups. There was significantly higher SLEDAI score in lupus nephritis group versus non-nephritis lupus group. There was significantly higher proteinuria and serum creatinine level in lupus nephritis group.

\section{Urinary CXCL10}

A statistically highly significant elevation in the level of urinary CXCL10 in lupus nephritis group versus non-nephritis lupus group was observed (Table I). 
Table I - Demographic, laboratory and activity score data in nephritis versus non-nephritis lupus patients.

\begin{tabular}{|l|c|c|c|c|}
\hline Variables & $\begin{array}{c}\text { Lupus nephritis } \\
\mathbf{N}=30\end{array}$ & $\begin{array}{c}\text { Non-nephritis lupus } \\
\mathbf{N}=30\end{array}$ & $\begin{array}{c}\text { Controls } \\
\mathbf{N}=30\end{array}$ & $\mathbf{P}$ \\
\hline Age & $22.8 \pm 3$ & $23.7 \pm 4$ & $24.4 \pm 1.6$ & $>0.05$ \\
\hline Gender & $3(10 \%)$ & $2(6.7 \%)$ & $2(6.7 \%)$ \\
Male & $27(90 \%)$ & $28(92.3 \%)$ & $28(93.3 \%)$ & $>0.05$ \\
Female & $6.8 \pm 3.3$ & $7.4 \pm 4$ & - & $>0.05$ \\
\hline Disease duration (years) & $12.8 \pm 2.5$ & $6.8 \pm 1.1$ & - & $<0.001$ \\
\hline SLEDAl score & $7.8 \pm 2.9$ & - & - & - \\
\hline Renal activity score & $2.1 \pm 1$ & $0.24 \pm 0.08$ & $0.11 \pm 0.03$ & $<0.001$ \\
\hline 24 urinary protein (g) & $35.6 \pm 11$ & $119 \pm 10.8$ & $109 \pm 11$ & $<0.001$ \\
\hline C3 (mg \%) & $5.2 \pm 1.4$ & $22.9 \pm 3$ & $21.2 \pm 2.4$ & $<0.001$ \\
\hline C4 (mg \%) & $1.3 \pm 0.3$ & $0.82 \pm 0.2$ & $0.79 \pm 0.3$ & $<0.001$ \\
\hline Creatinine (mg \%) & $270.5 \pm 62$ & $70.6 \pm 12$ & $30.5 \pm 16$ & $<0.001$ \\
\hline CXCL10 (Pg/dL) & & & \\
\hline
\end{tabular}

SLEDAI score, systemic lupus erythematosus disease activity index; C3, complement 3; C4, complement 4.

\section{Renal biopsy}

Tables II and III summarize the renal biopsy results in studied lupus nephritis patients.

Correlation between CXCL10 versus other variables among lupus nephritis group and non-nephritis lupus group

Tables IV and V demonstrate correlation between CXCL10 versus and other variables among lupus nephritis group and non-nephritis lupus group, respectively.

In lupus nephritis group, there was a statistically significant positive correlation between CXCL10 and urinary protein level,

Table II - Renal biopsy histopathology in lupus nephritis patients.

\begin{tabular}{|l|c|c|}
\hline Renal biopsy grade & No & $\%$ \\
\hline Diffuse proliferative & 16 & $53.3 \%$ \\
\hline Focal proliferative & 6 & $20 \%$ \\
\hline Mesangial proliferative & 8 & $26.7 \%$ \\
\hline
\end{tabular}

Table III - Distribution of renal biopsy grading in lupus nephritis patients.

\begin{tabular}{|l|c|c|}
\hline Renal biopsy grade & No & $\%$ \\
\hline I & 0 & 0 \\
\hline II & 8 & $26.7 \%$ \\
\hline III & 6 & $20 \%$ \\
\hline IV & 16 & $53.3 \%$ \\
G & 11 & $68.8 \%$ \\
S & 5 & $31.2 \%$ \\
\hline
\end{tabular}

G, global; S segmental.
Table IV - Correlation between CXCL10 versus other variables among nephritis group.

\begin{tabular}{|l|c|c|}
\hline \multirow{2}{*}{ Variables } & \multicolumn{2}{|c|}{ CXCL10 } \\
\cline { 2 - 3 } & $\mathbf{r}$ & $\mathbf{P}$ \\
\hline 24 urinary protein & 0.72 & $<0.001$ \\
\hline SLEDAl & 0.45 & $<0.001$ \\
\hline C3 & -0.42 & $<0.001$ \\
\hline C4 & -0.14 & $>0.05$ \\
\hline C1q & -0.03 & $>0.05$ \\
\hline Cr & 0.09 & $>0.05$ \\
\hline Renal activity score & 0.68 & $<0.001$ \\
\hline Biopsy grades & 0.84 & $<0.001$ \\
\hline
\end{tabular}

SLEDAI score, systemic lupus erythematosus disease activity index; $\mathrm{C} 3$, complement 3; C4, complement 4 ; Cr, creatinine.

SLEDAI, renal activity score and grade of renal biopsy, with an inverse correlation with $\mathrm{C} 3$.

In non-nephritis lupus group, statistically significant inverse correlation between CXCL10 with C4, without any significant correlation with other variables.

\section{Validity of CXCL10 in prediction of ne- phritis}

Using lupus nephritis (present or absent) and CXCL10 (positive or negative using best cut off of 93) as dichotomous variables, Table VI shows that CXCL10 was found to be a highly valid predictor of SLE nephritis with high sensitivity (100\%) and specificity $(98 \%)$. 
Table V - Correlation between CXCL10 versus other variables among non nephritis group.

\begin{tabular}{|l|c|c|}
\hline \multirow{2}{*}{ Variables } & \multicolumn{2}{|c|}{ CXCL10 } \\
\cline { 2 - 3 } & $\mathbf{r}$ & $\mathbf{P}$ \\
\hline 24 urinary protein & 0.12 & $>0.05$ \\
\hline SLEDAl & 0.10 & $>0.05$ \\
\hline C3 & -0.15 & $>0.05$ \\
\hline C4 & -0.43 & $<0.001$ \\
\hline C1q & -0.15 & $>0.05$ \\
\hline Cr & 0.16 & $>0.05$ \\
\hline Renal activity score & 0.22 & $>0.05$ \\
\hline
\end{tabular}

SLEDAI score, systemic lupus erythematosus disease activity index; $\mathrm{C} 3$, complement 3 ; $\mathrm{C} 4$, complement 4; Cr, creatinine.

Table VI - Validity of CXCL10 in prediction of nephritis.

\begin{tabular}{|l|c|}
\hline Variables & CXCl10 Pg/dL \\
\hline Best cut off & 93 \\
\hline AUC & 0.100 \\
\hline Sensitivity & $100 \%$ \\
\hline Specificity & $98 \%$ \\
\hline PPV & $100 \%$ \\
\hline NPV & $96 \%$ \\
\hline
\end{tabular}

AUC, area under the curve; PPV, positive predictive value; NPV, negative predictive value.

\section{DISCUSSION}

The present study addresses the urinary level of CXCL10 in a cohort of lupus nephritis versus non lupus nephritis patients and discloses the correlations with other variables including $24 \mathrm{~h}$ urinary proteins, SLEDAI score, C3, C4, serum creatinine, renal activity score and renal biopsy grading.

We found a significant higher urinary level of CXCL10 in lupus nephritis group compared to non-nephritis group. Furthermore, we found a significant in our trial to correlation between urinary level of CXCL10 and patients' variables.

In the nephritis group, there was statistically significant positive correlation between CXCL10 and $24 \mathrm{~h}$ urinary protein, SLEDAI, renal activity score, and grade of renal biopsy. However, an inverse correlation was detected with C3. Furthermore, we could not reveal any correlation with either $\mathrm{C} 4$ or serum creatinine. On the other hand, in non-nephritis lupus patients, the only correlation was an inverse correlation was detected with $\mathrm{C} 4$. Apart from the correlation detected with $\mathrm{C} 4$, these correlations appeared to be logic in respect of linking CXCL10 with disease activity in general and renal involvement in particular. With the limitation that our study is a cross-sectionall rather than a longitudinal one and it has a limited number of patients, CXCL10 may be suggested as a valid marker in prediction of nephritis in lupus patients, with a sensitivity of $100 \%$ and a specificity of $98 \%$. Further longitudinal studies are required to verify this suggestion.

It postulated that, clinically evident renal disease occurs in approximately half of the patients with SLE (12). Pathogenesis of lupus nephritis is multifactorial, most importantly immune complex deposition (13). In the normal kidney, production of inflammatory chemokines is low, but is significantly increased under pathophysiological circumstances such as ischemia, toxin exposure, or acute inflammation (14). CXCL10, one of the first chemokines identified, directs the trafficking of activated effector $\mathrm{CD}^{+}$and $\mathrm{CD}^{+} \mathrm{T}$ lymphocytes and other effector lymphocytes. CXCR3 is a chemokine receptor that is preferentially expressed on the surface of Th1 T cells. The receptor is activated by three related chemokines: IP-10/CXCL10, Mig/ CXCL9, and I-TAC/CXCL11. CXCR3 has been localized to infiltrating effector $\mathrm{T}$ cells of the Th1 type in a wide variety of human inflammatory diseases, including renal transplant rejection, glomerulonephritis, rheumatoid arthritis, and multiple sclerosis (15). Interestingly, IP-10 gene expression appeared to have consistent changes in relation to the histological class of lupus nephritis and correlated with the histological activity index. These findings suggest a specific role of these genes in the pathogenesis of lupus nephritis (16).

In renal allograft recipients it was found that for clinical and subclinical pathologies, urinary CXCL10 correlated well with the extent of tubulo-interstitial inflamma- 
tion (17). Ho et al. (18) performed a study which validated urinary CXCL10 as a noninvasive, sensitive, and specific marker for tubulitis in an independent cohort. It was also found to distinguish borderline, subclinical and clinical tubulitis from normal histology, and interstitial fibrosis and tubular atrophy. Further, peripheral blood mononuclear cells from SLE patients were shown to produce higher amounts of IP-10 in patients with active lupus nephritis as compared to healthy controls (19). Thus, in patients with active lupus, there seems to be increased production of the CXCL10 chemokine at the disease site, which may contribute to disease pathogenesis and increased urinary level.

Several previous studies tried to investigate levels of CXCL10 in SLE patients. Our study results are found to be consistent with work done by Avihingsanon et al. (7). In that study, pre-biopsy urine samples were collected from $26 \mathrm{LN}$ patients over a period of 6 months. It showed that the level of CXCL10 mRNAs in urine could distinguish class IV LN from others and that it was reduced in response to treatment. Also, Abujam et al. (20) showed increased urinary level of CXCL10 in active versus non active lupus nephritis. It comprised 136 patients with SLE including 78 active (46 active renal and 32 active non-renal). A previous study found active SLE patients to have increased levels of serum CXCL10 compared to non-active SLE patients, rheumatoid arthritis patients and healthy controls (21). Another study in which 40 SLE patients with renal disease, and 40 patients without renal disease were recruited, showed that plasma concentrations of CXCL10 were higher in SLE patients than in healthy individuals (22). Thomas et al reported that urinary IP-10 mRNA is a significantly better test for class IV lupus nephritis. Furthermore, patients who responded to therapy had significantly lower levels of IP-10, suggesting that IP-10 can be used as a barometer for treatment efficacy (23). To our knowledge, our study is amongst the earliest to address the correlation between CXCL10 and each of 24 hour urinary proteins, renal activity score, and SLEDAI score. Bauer et al. concluded that monitoring serum chemokine levels - including CXCL10- in SLE may improve assessment of current disease activity, the prediction of future flare, and overall clinical decision-making (24). A further longitudinal study may be required to validate its role as a biomarker for prediction and following up patients with lupus nephritis.

Finally, we can conclude that, urinary CXCL10 level is elevated in lupus nephritis patients, and was found to be linked with SLE disease activity in general and renal involvement in particular. It is a sensitive and specific marker for diagnosis of lupus nephritis, with a sensitivity of $100 \%$ and specificity of $98 \%$.

\section{REFERENCES}

1. Yap DY, Lai KN. The role of cytokines in the pathogenesis of systemic lupus erythematosus - from bench to bedside. Nephrology (Carlton). 2013; 18: 243-55.

2. Peschken CA, Katz SJ, Silverman E, Pope JE, Fortin PR, Pineau C, et al. The 1000 Canadian faces of lupus: Determinants of disease outcome in a large multiethnic cohort. J Rheumatol. $2009 ; 36$ : 1200-8.

3. Faurschou M, Starklint H, Halberg P, Jacobsen S. Prognostic factors in lupus nephritis: Diagnostic and therapeutic delay increases the risk of terminal renal failure. J Rheumatol. 2006; 33: 1563-9.

4. Neville LF, Mathiak G, Bagasra O. The immunobiology of interferon- gamma inducible protein $10 \mathrm{kD}$ (IP-10): A novel, pleiotropic member of the $\mathrm{C}-\mathrm{X}-\mathrm{C}$ chemokine superfamily. Cytokine Growth Factor Rev. 1997; 8: 207-19.

5. Kanda N, Shimizu T, Tada Y, Watanabe S. IL-18 enhances IFN- $\gamma$-induced production of CXCL9, CXCL10, and CXCL11 in human keratinocytes. Eur J Immunol. 2007; 37: 33850 .

6. Narumi S, Takeuchi T, Kobayashi Y, Konishi K. Serum levels of IFN-inducible protein-10 relating to the activity of systemic lupus erythematosus. Cytokine. 2000; 12: 1561-5.

7. Avihingsanon Phumesin P, Benjachat T, Akkasilpa S, Kittikowit V, Praditpornsilpa K, Wongpiyabavorn J, et al. Measurement of urinary chemokine and growth factor messenger RNAs: a noninvasive monitoring in lupus nephritis. Kidney Int. 2006; 69: 747-53.

8. Tan EM, Cohen AS, Fries JF, Masi AT, McShane DJ, Rothfield NF, et al. The 1982 revised criteria for the classification of systemic 
lupus erythematosus. Arthritis Rheum. 1982; 25: 1271-7.

9. Bombardier C, Gladman DD, Urowitz MB, Caron D, Chang CH. Derivation of the SLEDAI. A disease activity index for lupus patients.the committee on priognosis studies in SLE. Arthritis Rheum. 1992; 35: 630-40.

10. Weening JJ, D'Agati VD, Schwartz MM, Seshan SV, Alpers CE, et al. Classification of glomerulonephritis in systemic lupus erythematosus revisited. Kidney Int. 2004; 65: 521-30.

11. Petri M, Kasitanon N, Singh S, Link K, Magder L, Bae SC, et al. Systemic Lupus International Collaborating Clinics Renal Activity/ Response Exercise: comparison of agreement in renal response. Arthritis Rheum. 2008; 58: 1789-95.

12. Kasitanon N, Magder LS, Petri M. Predictors of survival in systemic lupus erythematosus. Medicine (Baltimore). 2006; 85: 147.

13. Lazennec G, Richmond A. Chemokines and chemokine receptors: new insights into cancer-related inflammation. Trends Mol Med. 2010; 16: 133-44.

14. Segerer S, Nelson PJ, Schlondorff D. Chemokines, chemokine receptors, and renal disease: From basic science to pathophysiologic and therapeutic studies. J Am Soc Nephrol. 2000; 11: 152-76.

15. Panzer U, Steinmetz OM, Reinking RR, Meyer TN, Fehr S, Schneider A, et al. Compartment-specific expression and function of the chemokine IP-10/CXCL10 in a model of renal endothelial microvascular injury. JASN. 2006; 17: 454-64.

16. Lu J, Szeto CC, Tam LS, Lai FM, Li EK, Chow KM, Li PK, et al. Relationship of intrarenal gene expression and the histological class of lupus nephritis.a study on repeat renal biopsy. J Rheumatol. 2012; 39:1942-7.
17. Hirt-minkowski P, Amica P, Ho J, Gao A, Bestland J, Hopfer H, et al. Detection of clinical and subclinical tubule-interstitial inflammation by the urinary CXCL10 chemokine in a real life setting. Am J Transplant. 2012; 12: 1811-23.

18. Ho J, Rush DN, Karpinski M, Storsley L, Gibson IW, Bestland J, et al. Validation of urinary CXCL10 as a marker of borderline,subclinical and clinical tubulitis. Transplantation. 2011; 92: 878-82.

19. Kong KO, Tan AW, Thong BY, Lian TY, Cheng YK, Teh CL, et al. Enhanced expression of interferon-inducible protein-10 correlates with disease activity and clinical manifestations in systemic lupus erythematosus. Clin Exp Immunol. 2009; 156: 134-40.

20. Abujam B, Cheekatla S, Aggarwal A. Urinary CXCL-10/IP-10 and MCP-1 as markers to assess activity of lupus nephritis. Lupus. 2013; 22: 614-23.

21. Fu Q, Chen X, Cui H, Guo Y, Chen J, Shen N, et al. Association of elevated transcript levels of interferon-inducible chemokines with disease activity and organ damage in systemic lupus erythematosus patients. Arthritis Res Ther. 2008; 10: R112.

22. Lit LC, Wong CK, Tam LS, Li EK, Lam CWK. Raised plasma concentration and ex vivo production of inflammatory chemokines in patients with systemic lupus erythematosus. Ann Rheum Dis. 2006; 65: 209-15.

23. Thomas JR, Blanco I, Putterman C. Urinary biomarkers in lupus nehritis. Clin Rev Allergy Immunol. 2011; 40: 138-50.

24. Bauer JW, Petri M, Batliwalla FM, Koeuth T, Wilson J, Slattery C, et al. Interferon-regulated chemokines as biomarkers of systemic lupus erythematosus disease activity: a validation study. Arthritis Rheum. 2009; 60: 3098-107. 